$\overline{\text { Note }}$

\title{
Antimicrobial Activity of Fullerenes and Their Hydroxylated Derivatives
}

\author{
HISAE AOSHIMA ${ }^{1 *}$, KEN KOKUBO ${ }^{2}$, SHOGO SHIRAKAWA ${ }^{2}$, MASAYUKI ITO $^{1}$, \\ SHUICHI YAMANA ${ }^{1}$, AND TAKUMI OSHIMA ${ }^{2}$ \\ Vitamin C60 BioResearch Corporation, Tatsunuma Tatemono Bldg., 9F, 1-3-19, \\ Yaesu, Chuo-ku, Tokyo 103-0028, Japan \\ ${ }^{2}$ Division of Applied Chemistry, Graduate School of Engineering, Osaka University \\ Yamadaoka, Suita, Osaka 565-0871, Japan
}

Received 30 May, 2008/Accepted 7 March, 2009

\begin{abstract}
The antimicrobial activities of fullerene $C_{60}$ and its derivatives against 6 kinds of bacteria and 2 kinds of fungi were evaluated. The tested samples were water-soluble fullerenes (polyvinylpyrrolidone (PVP)/ $\mathrm{C}_{60}, \boldsymbol{\gamma}$-cyclodextrin $(\boldsymbol{\gamma}-\mathrm{CD}) / \mathrm{C}_{60}$, and nano- $\left.\mathrm{C}_{60}\right)$ and 3 types of fullerenols $\left(\mathrm{C}_{60}(\mathrm{OH})_{12}, \mathrm{C}_{60}(\mathrm{OH})_{36} \cdot 8 \mathrm{H}_{2} \mathrm{O}\right.$, and $\left.\mathrm{C}_{60}(\mathrm{OH})_{44} \cdot 8 \mathrm{H}_{2} \mathrm{O}\right)$. Their activities were compared with those of $(+)$-catechin and hinokitiol from the viewpoint of future application to cosmetics. Although pristine $\mathrm{C}_{60}$ demonstrated no antimicrobial activity, fullerenols exhibited good antimicrobial activity against Propionibacterium acnes, Staphylococcus epidermidis, Candida albicans, and Malassezia furfur. In particular, $\mathrm{C}_{60}(\mathrm{OH})_{44}$ exhibited a strong and wide-ranging antimicrobial activity comparable to that of catechin. This compound exhibits antimicrobial activity via inhibition of microbial cell growth and not via bactericidal activity.
\end{abstract}

Key words : Fullerenol/Antibacteria/Antifungi/MIC.

The antimicrobial activity of fullerenes and their derivatives as a new class of carbon materials has attracted significant attention in the attempt to develop novel applications in the cosmetic and pharmaceutical industries. Mashino et al. (2003) reported that alkylated $\mathrm{C}_{60}$-bis (N,N-dimethylpyrrolidinium iodide) derivatives effectively inhibited bacterial cell growth. Pellarini et al. (2001) and Pantarotto et al. (2002) reported that several types of fullerene-peptides exhibited antibacterial activity against representative bacteria such as Escherichia coli and Staphylococcus aureus. On the other hand, fullerene $\left(\mathrm{C}_{60}\right)$ nanoparticles (particle size: less than $100 \mathrm{~nm}$ ) did not inhibit the growth of $E$. coli (Deguchi et al., 2006). In contrast, Lyon et al. (2005, 2006) reported that these particles exhibited antimicrobial activity against $E$. coli and Bacillus subtilis on a cultured minimal Davis (MD) medium. Recently, Kokubo et al.

*Corresponding author. Tel: +81-3-3517-3251, Fax : +813-3517-3260
(2008) have successfully synthesized highly watersoluble fullerenes (fullerenols) by using a novel hydrogen peroxide heating method. Fullerenols exhibit a superior and wide range of antioxidant activities against reactive oxygen species (ROS) by the radical scavenging activity of their allyl alcohol groups. It has been also reported that fullerenols inhibited brain cell damage by peroxide and damage of the bronchial asthma model (Tsai et al., 1997; Lai and Chiang, 1997). These studies have indicated the potential valuable applications of fullerenols. In order to investigate whether fullerenes could demonstrate antimicrobial activity, we investigated the minimum inhibitory concentration (MIC), minimum bactericidal concentration $(\mathrm{MBC})$, and minimum fungicidal concentration (MFC) of water-soluble fullerenes and their derivatives, i.e., fullerenols, against several types of bacteria and fungi.

Polyvinylpyrrolidone (PVP) entrapped $\mathrm{C}_{60}$ (PVP/ C60, FIG. 1 (a)) and $\gamma$-cyclodextrin ( $\gamma$-CD) bicapped $\mathrm{C}_{60}(\gamma-\mathrm{CD} / \mathrm{C} 60, \mathrm{FIG} .1$ (b)) were prepared 
(a) $\mathrm{PVP} / \mathrm{C}_{60}$.

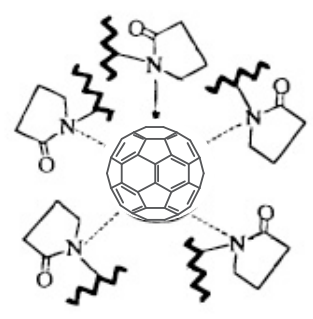

(b) $\gamma-\mathrm{CD} / \mathrm{C}_{60}$.

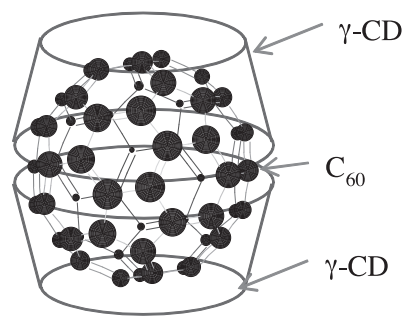

1. $\gamma-\mathrm{CD} / \mathrm{C}_{60}$

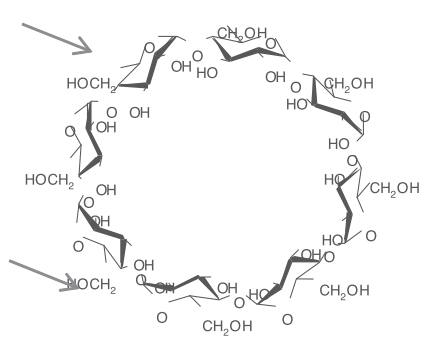

2. $\gamma-\mathrm{CD}$ (c) A possible isomer of $\mathrm{C}_{60}(\mathrm{OH})_{44}$.

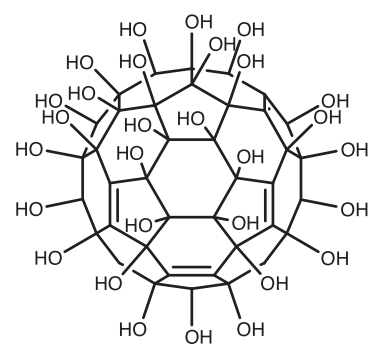

FIG. 1. Structures of water-soluble fullerene PVP/C60 (a), $\gamma-\mathrm{CD} / \mathrm{C} 60(\mathrm{~b})$, and a possible isomer of the fullerenol $\mathrm{C}_{60}(\mathrm{OH})_{44}(\mathrm{c})$.

according to the method used in previous studies (Yamakoshi et al., 1994; Andersson et al., 1992; Komatsu et al., 1999). Nano- $\mathrm{C}_{60}$ was produced by adapting a method from Deguchi et al. (2006). Fullerenol $\mathrm{C}_{60}(\mathrm{OH})_{12}$ and fullerenol $\mathrm{C}_{60}(\mathrm{OH})_{36}$ were synthesized (FIG. 2) according to the methods used in a previous study (Kokubo et al., 2008). Fullerenol $\mathrm{C}_{60}(\mathrm{OH})_{44}$ was produced by modifying the fullerenol $\mathrm{C}_{60}(\mathrm{OH})_{36}$ synthesis method (FIG. 1(c)).

E. coli, Bacillus sp., S. aureus (Methicillin-Resistant Staphylococcus aureus, MRSA), S. aureus (Methicillin-Sensitive Staphylococcus aureus, MSSA), and Staphylococcus epidermidis cells were inoculated into and cultured in Meuller-Hinton agar (MHA) medium at $35{ }^{\circ} \mathrm{C}$ for 16 to $20 \mathrm{~h}$ under aerobic conditions. Propionibacterium acnes cells were cultured in brucella agar supplemented with hemin (5

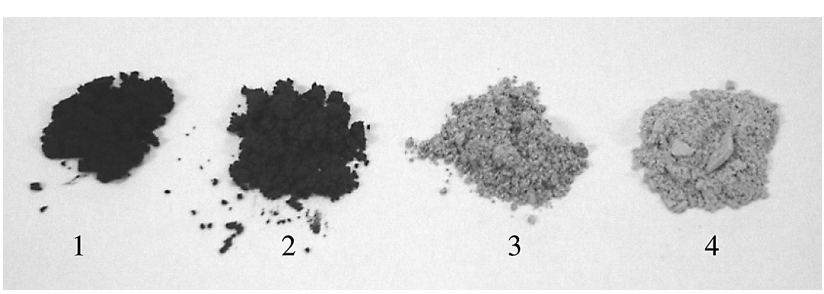

FIG. 2. Colors of fullerene $\mathrm{C}_{60}$ powder(1), fullerenol $\mathrm{C}_{60}(\mathrm{OH})_{12}(2), \mathrm{C}_{60}(\mathrm{OH})_{36} \cdot 8 \mathrm{H}_{2} \mathrm{O}(3)$, and $\mathrm{C}_{60}(\mathrm{OH})_{44}$ • $9 \mathrm{H}_{2} \mathrm{O}(4)$.

$\mu \mathrm{g} / \mathrm{ml})$, vitamin $\mathrm{K} 1$ (1 $\mu \mathrm{g} / \mathrm{ml})$, and $5 \%$ laked sheep blood at $35{ }^{\circ} \mathrm{C}$ for 42 to $48 \mathrm{~h}$ under anaerobic conditions. Candida albicans was cultured in RPMI1640 medium (Microbiology Systems, New York, USA) at $35{ }^{\circ} \mathrm{C}$ for 24 to $48 \mathrm{~h}$ under aerobic conditions. The Malassezia furfur cells were cultured in modified Leeming-Notman medium containing peptone (10 g/ $l$ ), glucose $(5 \mathrm{~g} / l)$, yeast extract $(0.1 \mathrm{~g} / l)$, ox bile (4 $\mathrm{g} / \mathrm{l})$, glycerol $(1 \mathrm{ml} / \mathrm{l})$, glycerol monostearate $(0.5 \mathrm{~g} /$ l), $0.5 \mathrm{ml}$ Tween-60 (0.5 ml/l), cow's milk (whole fat; $10 \mathrm{ml} / l$ ), and Alamar blue (final concentration, 10\%) at $32{ }^{\circ} \mathrm{C}$ for $3 \mathrm{~d}$ under aerobic conditions. All test samples were applied to agar plates or test tubes at 0.06 - $5120 \mu \mathrm{g} / \mathrm{ml}$.

The MICs of the prepared fullerenes and fullerenols against E. coli, Bacillus sp., S. aureus (MRSA), S. aureus (MSSA), S. epidermidis, and $P$. acnes were determined by the agar plate dilution method according to the Clinical and Laboratory Standards Institute (CLSI) methodology (CLSI M7-A7, 2006; CLSI M11A6, 2004; CLSI M100-S16, 2006). The MIC against C. albicans was determined by the minimal broth dilution assay according to the CLSI methodology (CLSI M27-A2, 2002). The MIC against $M$. furfur cultured in a modified Leeming-Notman medium was determined by the minimal broth dilution assay (Leeming et al., 1987; Garau et al., 2003; Lopez-Garcia, 2006). The MBC against $P$. acnes was determined by the method specified in the Clinical Microbiology Procedures Handbook (Isenberg, 2004). The MFC for M. furfur cultured on Dixon broth was determined by the minimal broth dilution assay (Hammer et al., 2000).

The MIC values of fullerenes against the bacteria and fungi investigated in this study are presented in Table 1. No adaptation effect was observed in any combination of fullerenes and microbial species tested. The antimicrobial activities of the well-known antimicrobial substances hinokitiol and $(+)$-catechin were evaluated and compared with those of fullerenes (Sawano, 1999). Hinokitiol demonstrated the strongest antimicrobial activity against all the bacteria and fungi used in this study. On the other hand, the MIC value of $(+)$-catechin was considerably 
TABLE 1. MIC values of various fullerene derivatives $(n=3)$.

\begin{tabular}{|c|c|c|c|c|c|c|c|}
\hline \multirow{2}{*}{ Strain } & \multirow{2}{*}{ No. } & \multicolumn{6}{|c|}{ MIC (mg/L) } \\
\hline & & $\mathrm{C}_{60}(\mathrm{OH})_{44}$ & $\mathrm{C}_{60}(\mathrm{OH})_{36}$ & $\mathrm{C}_{60}(\mathrm{OH})_{12}$ & $\mathrm{C}_{60}{ }^{a}$ & $(+)$-Catechin & Hinokitiol \\
\hline \multirow{3}{*}{ E. coli } & ATCC 25922 & $-{ }^{b}$ & - & - & - & 5120 & 8 \\
\hline & $\mathrm{Cl}^{\circ}-1$ & - & - & - & - & - & 8 \\
\hline & $\mathrm{Cl}-2$ & - & - & & - & - & 8 \\
\hline \multirow{3}{*}{ Bacillus sp. } & ATCC 12432 & - & - & - & - & - & 8 \\
\hline & NBRC 13719 & - & - & - & - & - & 16 \\
\hline & ATCC 6633 & - & - & - & - & 5120 & 8 \\
\hline \multirow{3}{*}{$\begin{array}{l}\text { S. aureus } \\
\text { (MRSA) }\end{array}$} & ATCC 33591 & 2000 & - & - & - & 5120 & 16 \\
\hline & $\mathrm{Cl}-3$ & 2000 & - & - & - & 5120 & 16 \\
\hline & $\mathrm{Cl}-4$ & - & - & - & - & 5120 & 16 \\
\hline \multirow{3}{*}{$\begin{array}{l}\text { S. aureus } \\
\text { (MSSA) }\end{array}$} & ATCC 25923 & - & - & - & - & 5120 & 16 \\
\hline & Cl-5 & 2000 & - & - & - & 5120 & 16 \\
\hline & Cl-6 & 2000 & - & - & - & 5120 & 16 \\
\hline \multirow{3}{*}{ S. epidermidis } & ATCC 12228 & 2000 & 2000 & - & - & 2560 & 0.5 \\
\hline & $\mathrm{Cl}-7$ & 2000 & 2000 & - & - & 2560 & 0.5 \\
\hline & Cl-8 & 2000 & 2000 & - & - & 2560 & 0.5 \\
\hline \multirow{3}{*}{ P. acnes } & ATCC 6919 & 1000 & - & - & - & 2560 & 64 \\
\hline & Cl-9 & 2000 & - & - & - & 2560 & 64 \\
\hline & $\mathrm{Cl}-10$ & - & - & - & - & 2560 & 64 \\
\hline \multirow{3}{*}{ C. albicans } & NBRC 1594 & 120 & 60 & 120 & - & - & 2 \\
\hline & Cl-11 & 120 & 60 & 500 & - & - & 2 \\
\hline & $\mathrm{Cl}-12$ & 120 & 60 & 250 & - & - & 2 \\
\hline \multirow{3}{*}{ M. furfur } & NBRC 0656 & - & - & - & - & 32 & 1 \\
\hline & NBRC 10987 & 60 & 120 & 250 & - & 16 & 1 \\
\hline & NBRC 10988 & 120 & 250 & 500 & - & 64 & 1 \\
\hline
\end{tabular}

${ }^{a}$ All PVP $/ C_{60}, \gamma-C D / C_{60}$, and nano- $C_{60}$ were tested. ${ }^{b}$ No antimicrobial activity $(-)$ was observed.

${ }^{\circ}$ Clinical isolates in the Mitsubishi Chemical Medicine Corporation (Tokyo, Japan).

lower than that of hinokitiol. $\mathrm{PVP} / \mathrm{C}_{60}\left(\mathrm{C}_{60}=270 \mathrm{mg} / \mathrm{l}\right.$; Fig. $1(\mathrm{a}))$ and $\gamma-C D / \mathrm{C}_{60}\left(\mathrm{C}_{60}=270 \mathrm{mg} / \mathrm{l}\right.$; FIG. $\left.1(\mathrm{~b})\right)$ at maximum water-soluble concentrations did not exhibit antimicrobial activity against any of the tested microorganisms. However, antimicrobial activity was exhibited by nano- $\mathrm{C}_{60}\left(\mathrm{C}_{60}=500 \mathrm{mg} / \mathrm{l}\right)$ against all microorganisms except E. coli. Nano- $\mathrm{C}_{60}$ contained 40 $\mathrm{mmol} / l$ of sodium dodecyl sulfate (SDS), which was used to facilitate its dissolution in water. The MIC values of nano- $\mathrm{C}_{60}$ completely corresponded with those of the SDS solution; therefore, the antimicrobial activity observed was considered to be due to SDS and not nano- $\mathrm{C}_{60}$. Thus, it was determined that nano- $\mathrm{C}_{60}$ did not exhibit antimicrobial activity. These results indicated that the water-soluble fullerenes did not possess antimicrobial activity.

On the other hand, fullerenols were observed to exhibit antimicrobial activity against several types of microorganisms. We examined the antimicrobial activity of fullerenol $\mathrm{C}_{60}(\mathrm{OH})_{12}$ dissolved in $5 \%$ dimethylsulfoxide (DMSO). It was confirmed that the $5 \%$ DMSO solution of $\mathrm{C}_{60}(\mathrm{OH})_{12}$ fullerenol did not show antimicrobial activity. However, $\mathrm{C}_{60}(\mathrm{OH})_{44}(\mathrm{FIG}$. 1(c)) exhibited strong and wide-ranging antimicrobial activity comparable to that of catechin. These suggested that the hydroxyl groups of fullerenes are responsible for their antimicrobial activity. In the case of $P$. acnes ATCC 6919 , the MIC value of $\mathrm{C}_{60}(\mathrm{OH})_{44}(0.68 \mathrm{~mol} / \mathrm{l})$ was superior to that of catechin $(8.8 \mathrm{~mol} / l)$ and comparable to that of hinokitiol $(0.39 \mathrm{~mol} / \mathrm{l}) \cdot \mathrm{C}_{60}(\mathrm{OH})_{44}$ is expected to have wide-ranging applications in the markets for household goods as well cosmetic ingredients. Further research was focused on important microorganisms such as $P$. acnes and $M$. furfur in dermatology. The $\mathrm{MBC}$ and MFC values of various fullerenols against each of the 10 tested strains of $P$. acnes and $M$. furfur were determined. Even at concentrations greater than $5,000 \mathrm{mg} / l$, none of the fullerenols exhibited MBC and MFC values against any of the tested strains (data not shown). This result indicates that the fullerenols exhibit antimicrobial activity through the inhibition of microbial cell growth.

Green tea extracts including catechin, nut oil extracts, and hinokitiol are known to contain antimicrobial agents, and are used for acne treatment. These agents generally possess a phenol structure with at least 1 hydroxyl group. It is believed 
that the phenol structure as well as amines and alcohols contribute to the antimicrobial activity by having a disrupting effect against the bacterial cell membrane. Especially in the case of catechin, Toda and Shimamura (1996) reported that B-ring of mother nucleus-bonded hydroxyl groups played a significant role for antimicrobial and bactericidal effect. The present study also supports the idea of such a role for hydroxyl groups.

Antimicrobial activity of fullerenols against fungi was stronger than that against bacteria. Fullerenols could have a greater tendency to interact with components such as $\beta$-glucan and chitin in the fungus cell-wall than peptidoglycan in the bacterial cellmembrane. The antifungal activities slightly become strong with an increase in the water solubility of fullerenols. Therefore, the water dispersible property of fullerenols may contribute to their antifungal activity. However, the detailed antimicrobial mechanism of fullerenes and their derivatives should be clarified in order to identify their novel applications in a wide range of industrial fields.

\section{REFERENCES}

Andersson, T., Nilsson, K., Sundahl, M., Westman, G., and Wennerström, O. (1992) C60 embedded in gammacyclodextrin: a water-soluble fullerene. J. Chem. Soc. Chem. Commun. 604-606.

Clinical and Laboratory Standards Institute/NCCLS. (2002) Reference Method for Broth Dilution Antifungal Susceptibility Testing of Yeasts; Approved Standard - Second Edition. CLSI/NCCLS document M27-A2 [ISBN 1-56238469-4]. Clinical and Laboratory Standards Institute/ NCCLS, Pennsylvania, USA.

Clinical and Laboratory Standards Institute. (2006) Performance Standards for Antimicrobial Susceptibility Testing; Sixteenth Informational Supplement. CLSI document M100-S16 [ISBN 1-56238-588-7]. Clinical and Laboratory Standards Institute, Pennsylvania, USA.

Clinical and Laboratory Standards Institute. (2006) Methods for Dilution Antimicrobial Susceptibility Tests for Bacteria that Grow Aerobically; Approved Standard Seventh Edition. CSLI document M7-A7 [ISBN 1-56238587-9]. Clinical and Laboratory Standards Institute, Pennsylvania, USA.

Clinical and Laboratory Standards Institute. (2004) Methods for antimicrobial susceptibility testing of anaerobic bacteria; approved standard-sixth edition, CLSI document M11-A6 [ISBN 1-56238-517-8]. Clinical and Laboratory Standards Institute, Pennsylvania, USA.

Deguchi, S., Mukai, S., Tsudome, M., and Horikoshi, K. (2006) Facile generation of fullerene nanoparticles by hand-grinding. Advanced Materials 18, 729-732.

Hammer, K. A., Carson, C. F., and Riley, T. V. (2000) In vitro activities of ketoconazole, econazole, miconazole, and Melaleuca alternifolia (tea tree) oil against Malassezia species. Antimicrob. Agents Chemother. 44, 467.

Isenberg, H. D. (2004) Clinical microbiology procedures handbook (2nd ed.) Washington, D.C.: American Society for Microbiology.

Kokubo, K., Matsubayashi, K., Tategaki, H., Takada, H., and Oshima, T. (2008) Facile synthesis of highly watersoluble fullerenes more than half-covered by hydroxyl groups. ACS Nano 2, 327-333.

Komatsu, K., Fujiwara, K., Murata, Y., and Braun, T. (1999) Aqueous solubilization of crystalline fullerenes by supramolecular complexation with -cyclodextrin and sulfocalix [8]arene under mechanochemical high-speed vibration milling. J. Chem. Soc. Perkin. Trans. 1, 29632966.

Lai Y. L., and Chiang L. Y. (1997) Water-soluble fullerene derivatives attenuate exsanguination-induced bronchoconstriction of guinea-pigs. J. Autonomic Pharmacol. 17, 229-235.

Leeming, J. P., and Notman, F. H. (1987) The distribution and ecology of Malassezia furfur and cutaneous bacteria on human skin. J. Clin. Microbiol. 25, 47-52.

Lopez-Garcia, B., Lee, P. H., and Gallo, R. L. (2006) Expression and potential function of cathelicidin antimicrobial peptides in dermatophytosis and tinea versicolor. J. Antimicrob. Chemother., 57, 877.

Lyon, D. Y., Fortner, J. D., Sayes, C. M., Colvin, V. L., and Hughes, J. B. (2005) Bacterial cell association and antimicrobial activity of a C60 water suspension. Environ. Toxicol. and Chem. 24, 2757-2762.

Lyon, D. Y., Adams, L. K., Falkner, J. C., and Alvarez, P. J. J. (2006) Antibacterial activity of fullerene water suspensions: effects of preparation method and particle size. Environ. Sci. \& Technol. 40, 4360-4366.

Mashino, T., Nishikawa, D., Takahashi, K., Usui, N., Yamori, T., Seki, M., Endo, T., and Mochizuki, M. (2003) Antibacterial and antiproliferative activity of cationic fullerene derivatives. Bioorg. Med. Chem. Lett 13, 43954397.

Pantarotto, D., Bianco, A., Pellarini, F., Tossi, A., Giangaspero, A., Zelezetsky, I., Briand, J.-P., and Prato, M. (2002) Solid-phase synthesis of fullerene-peptides. J. American Chem. Soc. 124, 12543-12549.

Pellarini, F., Pantarotto, D., Da Ros, T., Giangaspero, A., Tossi A., and Prato, M. (2001) A novel [60] fullerene amino acid for use in solid-phase peptide synthesis. Organic Lett. 3, 1845-1848.

Sawano, K. (1999) Activity of fragrance materials against skin resident microorganisms. Fragrance Journal. 8, 6168 (in Japanese).

Toda, M., and Shimamura, T. (1996) Antimicrobial activity of tea. Jpn. J. Food Microbiol. 12, 227-234.

Tsai, M. C., Chen Y. H., and Chiang L. Y. (1997) Polyhydroxylated $\mathrm{C}_{60}$, fullerenol, a novel free-radical trapper, prevented hydrogen peroxide- and cumene hydroperoxide-elicited changes in rat hippocampus invitro. J. Pharm. Pharmacol. 49, 438-445.

Yamakoshi, Y. N., Yagami, T., Fukuhara, K., Sueyoshi, S., and Miyata, N. (1994) Solubilization of fullerenes into water with polyvinylpyrrolidone applicable to biological tests. J. Chem. Soc. Chem. Commun. 517-518. 